\title{
SOCIOBIODIVERSIDADE E DIVERSIDADE EPISTÊMICA: REFLEXÕES SOBRE A EDUCAÇÃO DO CAMPO NO CENÁRIO ATUAL DO BAIXO TOCANTINS
}

\author{
Eliana Teles RODRIGUES ${ }^{1}$ \\ Universidade Federal do Pará \\ elianteles@gmail.com
}

Resumo: $O$ artigo reflete sobre elementos e ideias acerca da sociobiodiversidade $e$ da diversidade epistêmica, em sua contribuição ao curso Educação do Campo, a partir de conceitos e interpretações sobre o tema. Destacam-se as políticas socioambientais tendo como recorte para análise, a região do Baixo Tocantins, no município de AbaetetubaPA. Nesse sentido assinala-se que a valorização da sociobiodiversidade do lugar contribui para o diálogo entre os saberes acadêmicos e saberes locais $e$ assim dá suporte para a compreensão das relações socioambientais atuais, haja vista as problemáticas que os sujeitos enfrentam no campo social, ambiental, educacional e econômico. Problema.

Palavras-Chave: Sociobidiversidade, Educação do Campo, Políticas Socioambientais

\begin{abstract}
The article reflects on elements and ideas about socio-biodiversity and epistemic diversity, in its contribution to the "Educação no Campo" course (Education on the Countryside), based on concepts and interpretations about the theme. The socio-environmental policies are highlighted having as snip for analysis the "Baixo Tocantins" region (Low Tocantins), in the municipality of Abaetetuba-PA. In this matter it is notable that the appreciation of the sociobiodiversity of the place contributes to the dialogue between academic knowledge and local knowledge, and thus it gives support to the comprehension of current socio-environmental relations, considering the problematics that the subjects have to face on the social, environmental, educational and economical field.
\end{abstract}

Keywords: Sociobiodiversity, Educação do Campo, Socio-environmental Policies

\footnotetext{
${ }^{1}$ Geógrafa e doutora em Antropologia. Professora Adjunta I na Faculdade de Ciência Exatas e TecnologiaFACET/UFPA. Linhas de Pesquisa: Cartografias sociais e territorialidades; Ambiente, Tempo e Recursos.
} 


\section{Introdução}

O objetivo deste texto será relatar e refletir sobre elementos e ideias acerca da sociobiodiversidade e da diversidade epistêmica e sua contribuição na Educação do Campo. Verifica-se conceitos e interpretações que se apresentam em determinados contextos, como as políticas socioambientais, que no mais das vezes, invisibilizam, criminalizam, expropriam grupos sociais e suas práticas. O recorte para análise é a região do Baixo Tocantins, especificamente o municipio de Abaetetuba, a partir da realidade dos estudantes do curso Educação do Campo. O principal argumento ressalta a existencia de uma sociobiodiversidade que pode dialogar com os saberes acadêmicos e saberes locais, dando subsidios para a compreenção do mundo atual, haja vista as problemáticas que esses sujeitos enfrentam no campo social, ambiental, educacional e econômico.

\section{$O$ recorte regional}

Na Amazônia existe uma multiplicidade de identidades que configuram sua diversidade sociocultural, expressa por diferentes coletividades consoante denominações locais, tais como: ribeirinhos, seringueiros, quilombolas, indígenas, piaçabeiros, pescadores artesanais, castanheiros, artesãos e artesãs, indígenas que residem em cidades, quebradeiras de côco babaçu e peconheiros (coletores de açaí) dentre outras. Essas categorias de identidade acham-se agrupadas segunda forma organizativa própria, construindo, mediante mobilizações sucessivas, suas territorialidades específicas (ALMEIDA, 2012, p. 26).

Esses grupos sociais, ao longo do tempo tem construído um largo conhecimento acerca do ambiente em que vivem, ao qual remetem um valor de uso e um valor simbólico integrado numa complexa cosmologia (DIEGUES, 2005). Trata-se de povos que convivem, nomeiam e classificam os recursos de seu ambiente, os quais utilizam para os mais diversos fins e formas de uso. Por exemplo, os recursos faunísticos representam uma fonte importante de obtenção de proteína, remédio e de uma diversidade forma de uso social, espiritual e ao lazer. No cultivo essas formas de uso, destacam uma alta especialização, como a prática de manejo e adaptação de espécies, demonstrando que as paisagens "naturais" são socialmente 
construídas, a exemplo das "varjas" dos quilombolas do baixo rio Arari, no Marajó (TELES, 2014).

A sociodiversidade está relacionada aos modos de vida, territorialidade e ao meio ambiente. E no que diz respeito à Amazonia, cada ecossistema constitui nichos de saberes fruto dessa relação cultural, que resulta numa sociobiodiversidade, posto que se refere à complementaridade entre diversidade cultural e biológica, englobando também as diversidades cultural, populacional e os ecossistemas, constituindo assim, o que Diegues (2005) denomina etno-bio-diversidade.

Através de estudos sobre povos e comunidades tradicionais dessa região é possivel fazer um mapeamento de nichos espaciais identificados por esses grupos sociais, bem como compreender suas relações socioambientais, as ameaças a essa interação, a partir de processos e modelos desenvolvimentistas atuais. Juntas, essas sociedades étnicas constituem a memória viva da espécie humana (TOLEDO e BASSOLS, 2008) e tambem detem um acervo ético-moral, oferecendo assim, outro horizonte de sentido para a vida (PORTOGONÇALVES, 2014).

Dadas essas considerações, evidencia-se a importancia ecológica desses grupos sociais, mas não só. Para compreender isso é necessário romper com "as hierarquias etnocêntricas entre as diversas formas de conhecimento" (VELHO, 2010, p.22), ultrapassando ideias preservacionistas, para não incorrermos num imobilismo social, pois eles não conformam ecologias estáticas, constituem sim, aquilo que Ingold (2000) denomina "ecologias em movimento".

Considerando a assertiva, essas diferentes cosmovisões, contribuem para a diversificação de abordagens epistemológicas na literatura latinoamericana e põem em relevo a realidade social no contexto da Pan-amazônia, através de proposições acerca de sua sócio e biodiversidade, suas conjecturas e como elas tem sido apresentadas enquanto ideias e conceito.

Inserida nesse contexto, está a região do Baixo Tocantins, formada por dezenas de ilhas cortadas por rios, igarapés, furos, baías, praias e costas, por onde uma diversidade de grupos sociais circula, navega e vive. Um recorte específico desse contexto é o município de Abaetetuba, cujos povos e comunidades tradicionais tem criado estratégias e formas de uso 
de recursos naturais tendo em conta as dinâmicas e as técnicas de socialização destes recursos.

Nos ramais da terra firme, eles desenvolvem práticas agrícolas, ainda que seja em concorrencia desigual com os grandes projetos na forma de agrobusiness que aí tem se instalado nos últimos anos e vem substitundo a flora nativa pelo monocultivo de dendê. Nas ilhas e costa, praticam o extrativismo das palmeiras de açai (Euterpe Oleracea Mart.), miriti (Mauritia flexuosa L. f.) e a pesca, embora enfrentem a poluição ou contaminação pelos dejetos lançados pela lavagem das balsas ancoradas nas margens, ou aquelas advindas dos rejeitos de grandes projetos do polo de mineração, no vizinho município de Barcarena, dentre outros, como os resíduos de soja e milho lançados pelas balsas na Ilha do Capim.

São impactos que vem afetando o delicado equilíbrio ambiental do delta do Tocantins, que recebe o gigantesco volume d’água provenientes dos rios Amazonas e Tocantins e seus tributários, os quais conformam a grande diversidade de recursos naturais advindos dos seus diferentes ecossistemas.

Desse modo, tais grupos sociais enfrentam limitações para dar seguimento a seus modos de vida. Essas limitações se encontram tanto no campo biofísico quanto sociopolítico impossibilitando-os a exercerem outros métodos no manejo dos recursos quando se manifestam as intempéries naturais, dentre os quais, incidentes climáticos que podem causar impacto negativo nas colheitas, pesca, aquicultura e nos meios de vida das pessoas. A desconsideração dessas evidências e a cobiça em torno desses recursos tem provocado pressões sociais e ambientais, dando margem à vulnerabilidades ${ }^{2}$ que se manifestam ante as mudanças ambientais e políticas, as quais impactam diretamente os grupos sociais e demais seres vivos desse ambiente, de uma forma ou outra.

\footnotetext{
${ }^{2} \mathrm{O}$ termo "vulnerabilidade" tem uso científico inicialmente na geografia e em pesquisas voltadas aos riscos e ameaças naturais, todavia, atualmente assume posição de destaque em outros contextos de pesquisas e cada um dos domínios de conhecimento que usa o conceito tem sua própria maneira de defini-lo, o qual depende do contexto e do propósito de sua aplicação (Füssel, 2007). Não obstante trata-se de um conceito central para investigação no âmbito das alterações climáticas e mudança ambiental global, por isso engloba ciências a fins que lidam com temas como ecologia, saúde pública, pobreza e desenvolvimento, meios de subsistência e fome, sustentabilidade impactos e adaptação (Füssel, 2007:165). Destaca-se também investigações com base na análise de sistemas sócio-ecológicos, ou seja, nas interações entre condições humanas e condições biofísicas, e seus múltiplos fatores e processos (Turner II et al., 2003) e outros, que avaliam os possíveis impactos que as mudanças climáticas podem causar sobre pessoas, lugares e sistemas (Acosta-Michlik et al., 2008).
} 


\section{A sociobiodiversidade na Educação do Campo}

A ideia para a construção deste texto surgiu, a partir de experiência com estudantes do curso Educação do Campo de Abaetetuba, durante o Tempo Comunidade ${ }^{3}$ tem surgido a possibilidade de construir a autocartografia social ${ }^{4}$ dos espaços e territórios dos grupos sociais, os sujeitos do campo que vivem no contexto geoambiental acima referido. Através desse processo metodológico tem-se evidenciado situações sociais e geográficas diversas envolvendo os próprios estudantes, filhos de quilombolas, ribeirinhos, sitiantes de ramais, artesãos, pescadores e extrativistas, os quais tem apontado para um multiculturalismo que perpassa saberes diversos revelados nas práticas cotidianas desses sujeitos, os quais vem sendo relacionados aos saberes acadêmicos. Desse modo busca-se transcender às abordagens objetivistas, que definem o mapeamento como técnica, para tornar-se um componente da etnografia propiciando condições de possibilidades para a análise de uma situação social (ALMEIDA, 2012).

Nesse processo metodológico, aponta-se para uma diversidade de temas, os quais estão intrinsecamente ligados à biodiversidade, à sociodiversidade e se mesclam aos processos produtivos locais.

Durante trabalho de campo do Tempo Comunidade da disciplina Prática Pedagógica I, com os estudantes do curso Educação do Campo, turma 2015, adotou-se essa metodologia. A comunidade da Vila dos Murutinga, km 55 da PA 151, município de Abaetetuba, com cerca de trezentas familias, tem filhos e pais como alunos do curso. Os comunitários resistem ao domínio do monocultivo. Antes, no século XIX, quando ainda se chamava Vila da Cachaça, devido ao engenho ali localizado; depois veio o período da "colonização agrícola",

\footnotetext{
${ }^{3}$ No curso, este momento corresponde ao momento do trabalho prático dos estudantes em suas comunidades de origem, ou seja, busca-se realizar atividades solicitadas durante o Tempo Universidade, as quais devem ser orientadas pelo(s) docente(s).

${ }^{4}$ Nos trabalhos de pesquisa do Projeto Nova Cartografia Social da Amazônia (PNCSA), as técnicas de mapeamento social, visam analisar os processos diferenciados de territorialização, hoje em pauta na Amazônia, e sua relação com a emergência de identidades coletivas objetivadas em movimentos sociais. (ALMEIDA, 2012: 26)
} 
a partir dos anos 1970. Hkoje convivem com a insurgência do monocultivo do dendê e da concentração de terras por empresas do ramo como AGROPALMA e BIOVALE.

Durante a oficina, a comunidade tornou-se uma fonte de produção de informação cartográfica destacando-se a fala do senhor José Marques, 70 anos, que além de demonstrar profunda sabedoria das espécies cultivadas, critica o favorecimento ao agronegócio, em detrimento da agricultura familiar local:

Olha o dendê ele não veio pra cá de imediato, primeiro eles vieram ver se a terra era boa, ai ela era e é boa, depois eles vieram conversar com as famílias, se queriam vender a terra. Porque é o seguinte: quando eles vieram pra cá ver a terra,eles já tinham negociado com o governo. Então a vinda do dendê foi importante pra as pessoas arranjarem emprego, mas tirou uma parte da agricultura, porque onde plantavam não tão plantando mais, quem ficou ainda com um pouco de terra não teve crédito pra plantar e nem apoio do governo [...]. Tem outra coisa, por exemplo, a mandioca dá a farinha, dá a tapioca, tira o tucupi, dá a cachaça, ela dá até combustível, dá muita coisa. Ao contrário do dendê: ele só dá óleo, não dá alimentação pra ninguém se sustentar, ele é produzido pra vender (Senhor José de Oliveira, durante oficina da disciplina Prática Pedagógica I, no pátio da escola Professora Benedita Lima Araújo, abril de 2016).

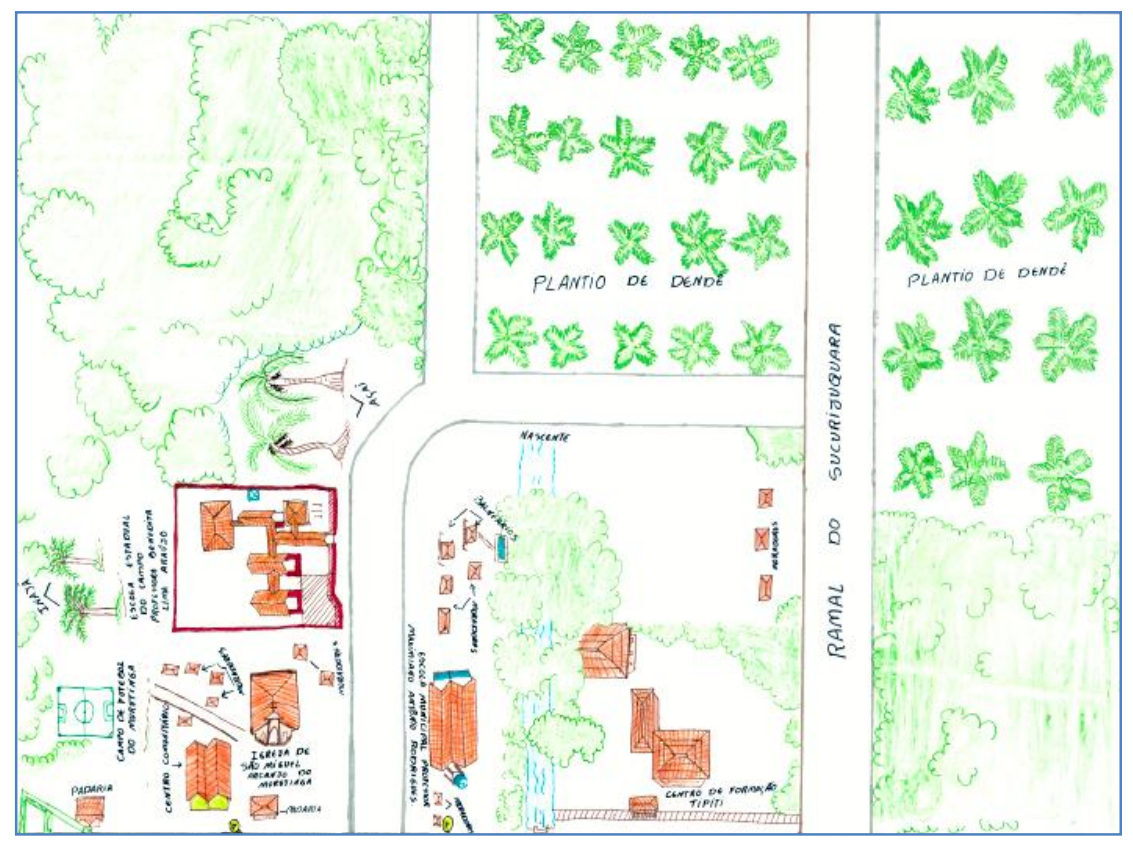

MARGENS - Revista Interdisciplinar Versão Digital - ISSN: 1982-5374
10 anos de Margens - Dossiê: Olhares campo o campo... VOL.10 N. 15. Dez 2016. (p. 42-52) 
Fig. 1: Croqui elaborado pelos moradores do Murutinga, em abril de 2016, durante oficina realizada no Tempo Comunidade da disciplina Prática Pedagógica I, turma 2015. Destaca-se o dominio da plantação de dendê nas cercanias, suprimindo o espaço da agricultura familiar.

O relato explicita o potencial conhecimento do camponês, sua praxis. E mais que isso, a dimensão política de sua luta, evidenciando que a Amazônia, mais que um bioma é um campo de luta. Esse viés suprime a visão naturalista que dá prevalência aos "biologismos" e aos "geografismos", e dá ênfase ao significado de "ecossistema amazônico" como produto de relações sociais e de antagonismos, seja pelo controle do patrimônio genético, do uso de tecnologias, das formas de conhecimento e de apropriação dos recursos naturais (ALMEIDA, 2008, p. 128).

Portanto são aportes que colocam um desafio epistêmico e pedagógico e nos conduz a pensar uma educação do campo a partir dessa diversidade de povos com culturas, linguagens, territorialidades, religiosidades, modos de vida tão diferenciados.

\section{Desafio epistemológico}

No que diz respeito á Amazônia, insiste-se aqui, em chamar a atenção para o cuidado com os “esquemas interpretativos” atribuídos à região (ALMEIDA, 2008). Sobretudo quando se trata de falar do bioma e sua sociodiversidade, geralmente o que se destaca são conceitos, tais como "natureza", "degradação ambiental", "comunidade", os quais, arraigados e legimitados no domínio do "senso comum erudito", na academia, estão também presentes nos discursos atuais, "classificando" e influenciando na vida dos grupos étnicos que a habitam.

São na realidade, produto de uma racionalidade naturalista/determinista fazendo-se presentes nos discursos econômicos e até filosóficos, nos quais os sujeitos "biologizados" são mera extensão dos recursos naturais, sem consciência nem direitos. Desse modo realizase uma clivagem entre cultura e natureza suprimindo os sujeitos da ação (ALMEIDA, 2008). Essas interpretações sobre a Amazõnia e até a América Latina, invisibilizam outros saberes, formas de conhecimento e a sociodiversidade. 
A assertiva aponta para a necessidade de uma abordagem epistemológica, que vise romper com esta racionalidade colonial naturalista e hegemônica, em que as pessoas deixem de ser meros indivíduos biológicos, produtos de "geografismos" e passam a assumir a posição de agentes sociais. Uma abordagem que tenha em conta a relação do ser humano com seus contextos e o mundo vivido, em que as pessoas passam a assumir a posição de sujeitos da ação ambiental, dando lugar a novos significados aos conceitos relacionados à categoria Amazônia (ALMEIDA, 2008, pp. 40-70).

A diversidade epistêmica, impõe também imaginar uma ecologia de saberes, que problematiza o encontro dos conhecimentos acadêmicos e dos povos locais. Nesse sentido, a crítica representada por Velho (2003) sobre o posicionamento reverso da antropologia nos países periféricos, nos permite entender as relações desiguais de poder existentes também na produção do conhecimento, que não nos leve a incorrer numa análise anacrônica da sociodiversidade que compõem a nação.

O autor aponta o perigo de formulações gerais em nome da "cultura", como se em nome da nação se realizasse a tutela dessa diversidade de povos que a compõem, e em nome dessa diversidade, a domesticação do outro (VELHO, 2003, p.13). Ao invés disso, recomenda buscar elaborações que permitam inserir-nos na ponta das questões de caráter epistemológico em diálogo com outros saberes, com um olhar não ressentido sobre as epistemes e os modelos centrais, mas observando, considerando outras possibilidades, ou seja, “desrespeitando limites com alegria” (VELHO, 2003, p.16).

\section{Desafio educacional}

Em que pese as discussões sobre os vocábulos "rural" e "urbano", a educação voltada ao segmento rural sempre foi relegada ao espaço marginal das políticas educacionais gestadas no dominio hegemônico do meio urbano que desconhece a forma concreta e específica do meio denominado campo. Sendo o campo, produto de práticas sociais e identidades constituídas, o que se materializa nessas políticas são ações desconectadas dessas caracterizações, as quais, muitas vezes, os inferioriza, os desqualifica ou estereotipa. Não diferente são os discursos academicistas, que, valendo-se de um "conhecimento superior" 
terminam reificar o campo como sendo apenas produtor de alimentos e mão de obra desqualificada.

Mas é fato que a escola tem sido por várias vezes, reprodutora de uma colonialidade do saber, seja qual for a nomenclatura: urbana ou rural, campo ou cidade. Esse asserto aponta para uma metodologia que transforme as diferenças em possibilidades de construção de novos saberes e valores, que tenham em conta as cosmologias dos sujeitos, suas narrativas sobre seu ambiente natural, sua arte, sua ciência e sua técnica, dando vez a um saber que emerja da subalternidade (MIGNOLO, 2003).

Dar vez ao paradigma de transição na perspectiva de um olhar que emerja da "racionalidade subalterna" (MIGNOLO, 2003) deveria ser tomada como fonte de inspiração para pensar uma pedagogia que valorize as cosmologias dos sujeitos do campo. Isto implica ir para além de abordagens simplistas e nos desafia a repensar as nossas relações com os conhecimento e oportunizar outras epistemes, outras racionalidades (PORTOGONÇALVES, 2014).

Desafia-se, portanto, o ensino, a democratizar-se partindo de um trabalho de inclusão dos diferentes, tendo em conta que, quem educa não é a escola, mas a realidade, e esta, não fica estanque lá fora, deve ser trazida para dentro da sala (CALDART, 2001).

\section{Notas conclusivas: resistência e ameaças à sociodiversidade na Amazonia}

Nas últimas décadas notam-se transformações advindas de influências ou pressões externas como as dos grandes projetos instalados naAmazônia; aumento da demanda por produtos da região, principalmente o açai (Euterpe oleracea Mart.) que demanda acesso a linhas de crédito, como resposta às demandas de mercado. Esta pressão cada vez maior sobre a natureza originária nas várzeas e terras firmes do Baixo Tocantins, já vem alterando o cotidiano dos ribeirinhos e o agroecossistema onde vivem.

Muitas vezes, as políticas e investimentos públicos contribuem para isso, posto que aplicados sem entendimento do papel da biodiversidade na vida dos povos tradicionais dessa região, não tem em conta os etnoconhecimentos que eles detêm acerca da biodiversidade local. Também não se considera como os sujeitos utilizam os recursos nesse contexto 
territorial, suas práticas de manejo, a partir da compreensão de suas estratégias, seja no processo de construção da territorialidade, os riscos e a vulnerabilidade socioambiental aos quais estão expostos.

Assim, abrem passagem para os novos "predadores do territorio", através da imposição de um paradigma econômico sob forma de política social e que se apresenta como a solução para o desenvolvimento e crescimento econômico: o agronegócio. Fruto de estratégia global para a recuperação da economia, nos países emergentes as políticas sociais e neodesenvolvimentistas se manifestam com maior força através da expansão extrativista e agrícola, pois a crescente demanda na produção de alimentos força a ampliação das fronteiras agrícolas mundiais que se encontram majoritariamente concentradas em países pobres ou emergentes, mas que detém extensas áreas florestais e propícias à agricultura.

Portanto, a sociodiversidade implica a existencia de políticas que apontem para a sustentabilidade ambiental, para a continuidade sociocultural e qualidade de vida de povos que dela necessitam, assim como a qualidade de vida dos mesmos. Tendo em vista que, a natureza é diversa e a sociedade constitui experiências que expressam-se pela diversidade.

\section{Referências Bibliográficas}

Acosta-Michlik, L., Espaldon, V. 2008. Assessing vulnerability of selected farming communities in the Philippines based on a behavioural model of agent's adaptation to global environmental change. Global Environmental Change 18: 554-563.

Almeida, A. W. B. 2008. Terras de quilombos, terras indígenas, "babaçuais livres", "castanhais do povo", faxinais e fundos de pastos: terras tradicionalmente ocupadas (Coleção “Tradição e ordenamento jurídico”). 2. ed. Manaus: PGSCA-UFAM, 192p.

.2013. Mapas situacionais e categorias de identidade na Amazônia. In Almeida, W. B de, Farias Junior, E de A. (Org.). Povos e comunidades tradicionais: nova cartografia social. Catálogo. Manaus: UEA Edições.

Caldart, R. S. 200. O MST e a formação dos sem terra: o movimento social como princípio educativo. São Paulo: Estudos Avançados.

Diegues, A. C. S. \& Arruda, R. S. V. 2001. Saberes tradicionais e biodiversidade no Brasil. Brasília: Ministério do Meio Ambiente; São Paulo: Universidade de São Paulo, 119p. 
DIEGUES, A. C. S. 2005. Sociobiodiversidade. Encontros e caminhos: formação de educadoras(es) ambientais e coletivos educadores. Brasília: MMA,

Füssel, H-M. 2007. Vulnerability: a generally applicable conceptual framework for climate changeresearch. Global Environmental Change 17: 155-167.

Ingold, T. 2000. The Perception of the Environment: Essays in Livelihood, Dwelling and Skill.

Mignolo, W. Histórias locais/Projetos Globais: Colonialidade, Saberes Subalternos e Pensamento Liminar. Belo Horizonte: Editora UFMG, 2003. 505 p

Porto-Gonçalves, C. W. 2014. Sustentabilidade em Debate - Brasília, v. 5, n. 3, p. 159-168, set/dez.

Posey, D. A. 1986.. Introdução. Etnobiologia: teoria e prática. In: Ribeiro, B. G. (Editor). Suma Etnológica Brasileira: Etnobiologia, pp. 16-25.

Toledo, V. Bassols, N, B. 2008. Memória Biocultural: la importancia ecológica de las sabidurías tradicionales. Icaria editorial, s.a. Barcelona: España.

Teles, E. T. R. 2014. "A gente faz a varja": territorialidade, estratégia de uso de recursos, identidade e conflitos na Ilha de Marajó, Pará. Tese de doutorado. Programa de PósGraduação em Antropologia-PPGA/UFPA, 250f.

Turner II, B. L. et al. 2003. Illustrating the coupled human-environment system for vulnerability analysis: Three case studies. Proc. Nat. Acad. Sci. 100 (14): 8074-8079.

West, J. J., Hovelsrud, G. K. 2008. Climate change in northern Norway: Toward an understanding of socio-economic vulnerability of natural resource-dependent sectors and communities. Cicero Report 4, 37 p.

Velho, O. 2003. A pictografia da tristesse uma antropologia do nation-building nos tropicos. I LH A - Florianópolis, v.5, n.1, p. 5-22.

2010. Diversidade cultural e a CT \& I com desenvolvimento social. In Almeida, A. W.

B de (Org.) [et. al]. Conhecimentos tradicionais e territórios na Pan-Amazonia. Projeto Nova Cartografia Social. Manaus: UEA Edições. vol 1, n. 1, p. 2-25. 